\title{
miR-1 reverses multidrug resistance in gastric cancer cells via downregulation of sorcin through promoting the accumulation of intracellular drugs and apoptosis of cells
}

\author{
LANG-MEI DENG ${ }^{1}$, TAN TAN ${ }^{2}$, TIAN-YI ZHANG ${ }^{1}$, XUE-FEI XIAO ${ }^{1}$ and HUAN GU ${ }^{3}$ \\ ${ }^{1}$ Critical Care Center, The Third Xiangya Hospital of Central South University, Changsha, Hunan 410013; \\ ${ }^{2}$ Department of Inspection, Chenzhou No.1 People's Hospital, Chenzhou, Hunan 423000; \\ ${ }^{3}$ Department of Gastroenterology, Xiangya Hospital of Central South University, \\ Changsha, Hunan 410008, P.R. China
}

Received April 4, 2018; Accepted May 22, 2019

DOI: 10.3892/ijo.2019.4831

\begin{abstract}
Gastric cancer (GC) is one of the most common cancers worldwide and results in the second greatest rate of cancer-associated mortality globally. Multidrug resistance (MDR) often develops during the chemotherapy, resulting in the failure of treatment. To investigate the molecular mechanism of MDR, the roles of microRNA (miR)-1 were studied in GC. Reverse transcription-quantitative polymerase chain reaction and western blotting were used to investigate the expression levels of miR-1 and sorcin in SGC7901/ADM and SGC7901/VCR cell lines. The effect of miR-1 on the half maximal inhibitory concentration $\left(\mathrm{IC}_{50}\right)$, cell apoptosis rates and drug accumulation was uncovered by MTT assay and flow cytometric analysis. Furthermore, dual-luciferase assay and western blotting were used to determine the target of miR-1 in GC. It was demonstrated that miR-1 was highly downregulated in MDR GC cell lines, including SGC7901/ADM and SGC7901/VCR. Overexpression of miR-1 in MDR GC cells decreased $\mathrm{IC}_{50}$, but increased the cell apoptosis rates and promoted the drug accumulation in cancer cells. Dual-luciferase activity assay indicated that sorcin was the target of miR-1 in GC. In addition, overexpression of sorcin could partially reverse the effect of miR-1 in MDR GC cells. The role of miR-1 in MDR GC cells makes it a potential therapeutic target for a successful clinical outcome.
\end{abstract}

\section{Introduction}

Gastric cancer (GC) is one of the most common cancers worldwide and results in the second greatest rate

Correspondence to: Dr Lang-Mei Deng, Critical Care Center, The Third Xiangya Hospital of Central South University, 138 Tongzipo Road, Yuelu, Changsha, Hunan 410013, P.R. China

E-mail: langmei18@163.com

Key words: gastric cancer, multidrug resistance, microRNA-1, sorcin cancer-associated mortality globally (1). Although surgery is an effective therapeutic strategy for patients with resectable tumors, the majority of patients with GC, particularly in China, are diagnosed at an advanced and are thus unresectable at that clinical stage (2). For those patients, chemotherapy becomes the preferred treatment method. However, multidrug resistance (MDR) often develops during chemotherapy, resulting in the failure of treatment (2-4). Therefore, strategies that can reverse MDR of GC cells have a notable impact on the success of chemotherapy. To generate an efficient strategy for reversing MDR, it is important to discover novel cancer-associated key molecules and MDR-associated mechanisms in GC cells.

Sorcin is a soluble resistance-associated calcium-binding protein, which is expressed in many human tissues, with especially high levels in the bones, heart, kidneys and skin $(5,6)$. However, it was also demonstrated that sorcin was overexpressed in many types of cancer, including leukemia, breast cancer and GC (7-9). Sorcin gene is positioned in the same amplicon of other genes associated with the resistance to chemotherapeutic agents in cancer cells. Therefore, in multidrug-resistant cancer cells, sorcin was recognized as 'resistance-associated' (10). For instance, a high sorcin expression level in leukemia patients indicated poor chemotherapeutic response and poor prognosis (5). Previous studies have demonstrated that sorcin overexpression is closely associated with the MDR of GC (11-13). Silencing sorcin by shRNA, Xu et al (14) demonstrated that the drug chemosensitivity in myeloma KM3/DDP and U266/ADM cell lines was enhanced. In MDA-MB-231 breast cancer cells, $\mathrm{Hu}$ et al (15) demonstrated that sorcin depletion by RNA interference inhibited epithelial-to-mesenchymal transition and suppressed breast cancer metastasis in vivo. It has been suggested that suppressing sorcin may have the potential to improve the sensitivity of GC cells to drugs.

MicroRNAs (miRNAs or miRs), small non-coding RNA molecules with 22 nucleotides, control gene expression levels by degrading mRNA at the posttranscriptional level (16). The binding sites of miRNAs are usually the 3'-untranslated region (UTR) sequences of mRNAs. Upon the hybridization of miRNAs and mRNA, the target gene is 
downregulated (17). During GC development, progression and therapeutic processes, $>200 \mathrm{miRNAs}$ have been demonstrated to be involved (18). Furthermore, the MDR of various types of cancer is also regulated by miRNAs (18). Among those miRNAs, miR-1 is decreased in various human cancers, which indicated that it may be a potential therapeutic target for cancer treatment (18). Conversely, the prediction of Targetscan and previous studies indicated that miR-1 may directly target sorcin. It was also reported that the expression level of miR-1 was associated with the chemoresistance of GC and lung cancer $(19,20)$. Therefore, the interaction between miR-1 and sorcin in the development of MDR of GC is of interest for the diagnosis and treatment of MDR GC.

It has previously been reported that miR-1 is significantly downregulated in GC cells (19). However, the mechanism of miR-1 in regulating the MDR of GC cells remains unclear. In the present study, the role of miR-1 and sorcin in MDR GC cells was assessed using SGC7901/adriamycin (ADM) and SGC7901/vincristine (VCR) resistant cell lines, which have been widely used as the model of MDR GC $(21,22)$. Doxorubicin, also known as ADM, is an anthracycline-based anti-tumor agent and is an effective FDA-approved drug for GCs (23). Vincristine is also a common drug for cancer thermotherapy for many types of cancer, such as acute myeloid leukemia, small cell lung cancer and neuroblastoma (24-26). The aim of the present study was to provide an insight into the molecular mechanism of MDR in GC cells. It was demonstrated that miR-1 was significantly downregulated in all MDR GC cells lines. By overexpressing miR-1 in those MDR GC cell lines, the apoptosis and drug accumulation rates were increased. In addition, the results demonstrated that sorcin was one of the targets of miR-1 in GC. Overexpression of miR-1 in GC cells inhibited sorcin and then promoted the cell apoptosis and drug accumulation. Therefore, miR-1 may be used as a small therapeutic molecule and potential target for new drug discovery in GC.

\section{Materials and methods}

Cell culture and treatment. The GC cell lines, SGC7901, SGC7901/VCR and SGC7901/ADM, were obtained from the Shanghai Institutes for Biological Sciences Cell Resource Center (Shanghai, China). The cells were cultured with RPMI-1640 medium (Thermo Fisher Scientific, Inc.) with $10 \%$ fetal bovine serum (Thermo Fisher Scientific, Inc.), penicillin and streptomycin at $37^{\circ} \mathrm{C}$ in a humid atmosphere $\left(5 \% \mathrm{CO}_{2}, 95 \%\right.$ air). For drug treatment, the SGC7901, SGC7901/ADM and SGC7901/VCR cells were cultured in the same medium with the addition of $0,0.5,1,2,4,8,16$ or $32 \mu \mathrm{g} / \mathrm{ml} \mathrm{ADM}$, or $0,0.01,0.1,1,5,10$ or $20 \mu \mathrm{g} / \mathrm{ml} \mathrm{VCR}$ and MTT assay was performed $24 \mathrm{~h}$ later. The half maximal inhibitory concentration $\left(\mathrm{IC}_{50}\right)$ was determined by plotting the relationship between the concentrations of drugs and the cell viabilities.

Cell transfection. miR-1 mimics, scramble miRNA negative control (miR-NC) and miR-1 inhibitors were synthesized by Shanghai GenePharma Co., Ltd.. The sequences were as follows: miR-1 mimic, 5'-UGGAAUGUAAAGAAGUAUG UAU-3' (sense) and 5'-ACAUACUUCUUUACAUUCCAUU-3' (antisense); miR-NC, 5'-UUCUCCGAACGUGUCACGUTT-3' (sense) and 5'-ACGUGACACGUUCGGAGAATT-3' (antisense); miR-1 inhibitor, 5'-UUCAGUUAUCACAGUACU GUA-3'; inhibitor NC, 5'-CAGUACUUUUGUGUAGUA CAA-3'. SGC7901, SGC7901/ADM and SGC7901/VCR cells were transfected with $100 \mathrm{nM}$ miR-1 mimics or miR-1 inhibitor for miR-1 overexpression and knockdown, respectively. miR-NC (100 $\mathrm{nM})$ and inhibitor $\mathrm{NC}(100 \mathrm{nM})$ were used as negative controls. Transfection was conducted using Lipofectamine 2000 reagent (Invitrogen; Thermo Fisher Scientific, Inc.) according to the manufacturer's protocol. Six hours post-transfection, the medium was changed with fresh medium. At $48 \mathrm{~h}$ post-transfection, the cells were used in subsequent experiments.

MTT assay. In 96-well plates, the GC cells (2,000 cells/well) were cultured in RPMI-1640 medium for $24 \mathrm{~h}$ following the different treatments. Then, $10 \mu \mathrm{l}$ MTT was added into the culture medium for $60 \mathrm{~min}$ at $37^{\circ} \mathrm{C}$, followed by the addition of $100 \mu \mathrm{l}$ dimethyl sulfoxide in each well to dissolve the resulting crystals by shaking for $10 \mathrm{~min}$ at room temperature. Then, the optical absorbance at $490 \mathrm{~nm}$ was measured using a microplate reader.

Apoptosis analysis by flow cytometry. For the apoptosis analysis, the cells were transfected with miR-NC, miR-1 mimics and miR-1 inhibitors. Then, the Annexin V-FITC/PI Apoptosis Detection kit (BD Biosciences) was used to stain each sample, which were then analyzed by flow cytometry. The quantitative analysis of the percentage of the apoptosis cells was performed using FlowJo v10 (Tree Star, Inc.,).

Reverse transcription-quantitative polymerase chain reaction $(R T-q P C R)$. The total RNA from the GC cells were collected using TRIzol reagent (Life Technologies; Thermo Fisher Scientific, Inc.) according to the manufacturer's instructions. Then, the reverse transcription of cDNA from the RNAs was performed with TaqMan Reverse Transcription reagents (Life Technologies; Thermo Fisher Scientific, Inc.). The analysis of expression levels of miR-1, B cell lymphoma (BCL)-2, BCL-2-associated $\mathrm{X}$ protein (Bax), c-fos, c-jun and sorcin were performed using TaqMan microRNA assay kits (Applied Biosystems; Thermo Fisher Scientific, Inc.). The primer sequences used for miR-1 were as follows: Forward, 5'-GCGGCTGGAATGTAAAGAAGT-3'; and reverse, 5'-CGG CCCAGTGTTCAGACTAC-3'. The sequences for BAX were as follows: Forward, 5'-CTGACGGCAACTTCAACTGGG-3'; and reverse, 5'-CAACCACCCTGGTCTTGGATC-3'. The sequences forc-fos were as follows: Forward,5'-CTTACTACCA CTCACCCGCAG-3'; andreverse,5'-GCCTCCTGTCATGGTC TTCAC-3'. The sequences for c-jun were as follows: Sense, 5'-GTGCCGAAAAAGGAAGCTGG-3'; and reverse, 5'-CTG CGTTAGCATGAGTTGGC-3'. The sequences for BCL-2 were as follows: Forward, 5'-GGATCCAGGATAACGGA GGC'; and reverse, 5'-GATAGGCACCCAGGGTGATG-3'. The sequences for sorcin were as follows: Forward, 5'-GGAGA CTTGCCGGCTTATGG-3'; and reverse, 5'-CACAGCCTGG GGACTCAACC-3'. The sequences for GAPDH were as follows: Forward, 5'-GTCAACGGATTTGGTCTGTATT-3'; and reverse, 5'-AGTCTTCTGGGTGGCAGTGAT-3'. The 
sequences for U6 were as follows: Forward, 5'-TGCGTTCCCT TTGTCATCCT-3'; and reverse, 5'-AACGCTTCACGAATTT GCGT-3'. The primers were synthesized by Sangon Biotech Co., Ltd. The thermocycling conditions were: $95^{\circ} \mathrm{C}$ for $10 \mathrm{~min}$, then 45 cycles of $94^{\circ} \mathrm{C}$ for $15 \mathrm{sec}, 60^{\circ} \mathrm{C}$ for $40 \mathrm{sec}$, and $72^{\circ} \mathrm{C}$ for $45 \mathrm{sec}$. The $2^{-\Delta \Delta \mathrm{Cq}}$ method was used to calculate the relative fold change in expression compared with a reference sample (27).

Western blot analysis. Total cellular proteins were extracted from cells using cell lysis buffer (Beijing Solarbio Science \& Technology Co., Ltd.) and the amount of protein was determined by bicinchoninic acid assay. Then, the proteins $(50 \mu \mathrm{g})$ were separated by $10 \%$ SDS-PAGE and then transferred to polyvinylidene difluoride membranes (EMD Millipore). Subsequently, 5\% milk was used to block the membrane for $1 \mathrm{~h}$ at room temperature followed by incubation overnight at $4{ }^{\circ} \mathrm{C}$ with primary antibodies against MDR protein $1 / \mathrm{P}$-glycoprotein (MDR1/P-gp; cat. no. 13342; 1:1,000), MDR-associated protein 1 (MRP-1; cat. no. 72202; 1:600), Bax (cat. no. 2774; 1:800), c-fos (cat. no. 4384; 1:1,000), c-jun (cat. no. 9165; $1: 800$ ) and BCL-2 (cat. no. 4223; 1:600) from Cell Signaling Technology, Inc., and against sorcin (cat. no. A6751, 1:1,000) from ABclonal. Membranes were then incubated at room temperature for $2 \mathrm{~h}$ with horseradish peroxidase-conjugated secondary antibodies (goat anti-rabbit; cat. no. ZB-2301; 1:5,000; and goat anti-mouse; cat. no. ZDR5307; 1:1,500; OriGene Technologies, Inc.). An enhanced chemiluminescence detecting system (iBright CL1000 imaging system; Thermo Fisher Scientific, Inc.) was used to quantify the expression levels. The bands were quantified using Image $\mathrm{Lab}^{\mathrm{TM}}$ software (Bio-Rad Laboratories, Inc.). $\beta$-actin (cat. no. AC004; 1:1500; ABclonal) was used as loading control.

Dual luciferase activity assay. The dual luciferase activity assay was used to confirm the target of mir-1. The potential target site of miR-1 on the sorcin gene was predicted using the miRDB database (http://mirdb.org/). Fragments containing the 3'UTR target sites of sorcin were amplified and then cloned into psiCHECK (Invitrogen; Thermo Fisher Scientific, Inc.). Forward and reverse PCR primers carried a 5 ' overhang that contained SpeI and HindIII recognition sites, respectively. Then, the sorcin 3'-UTR fragment was cloned into the dual luciferase reporter vector psiCHECK and the recombinant plasmid was named psiCHECK-wt. The miR-1 targeting sequence in the above sorcin 3'UTR reporter plasmid was also mutated and named psiCHECK-mut. Then, the SGC7901 cells were transfected with the psiCHECK-wt, psiCHECK-mut, miR-NC and miR-1 mimic using Lipofectamine 3000 for $48 \mathrm{~h}$ (Thermo Fisher Scientific, Inc.). The Dual-Luciferase assay kit (Promega Corporation) was used to measure the luciferase activities in transfected cells following to the manufacturer's information. The luciferase activity, normalized against protein concentration, was expressed as a ratio of firefly luciferase to Renilla luciferase units.

Drug accumulation assay. The treated GC cells ( $2 \times 10^{6}$ cells $/$ well in a 6-well plate) were collected and incubated with $0.3 \mu \mathrm{M}$ Rhodanmin 123 (Rho123; cat. no. R8004; Sigma-Aldrich; Merck KGaA) in RPMI-1640 medium for $90 \mathrm{~min}$ at $37^{\circ} \mathrm{C}$.
Then, the cells were washed with ice-cold PBS twice and finally suspended in $500 \mu 1$ ice-cold PBS. Beckman CytoFLEX flow cytometry (CytExpert 2.0; Beckman Coulter, Inc.) was used to quantify the Rho123 accumulation in cells with excitation at $488 \mathrm{~nm}$ and emission at $530 \mathrm{~nm}$.

Statistical analysis. Data are presented as the means \pm standard deviation of at least three separate experiments. The difference between two groups was analyzed by unpaired two-tailed Student's t-test. One-way analysis of variance was used for comparison among multiple groups and multiple comparisons were further performed using post hoc Tukey's test. $\mathrm{P}<0.05$ was considered to indicate a statistically significant difference.

\section{Results}

Expression of miR-1 and sorcin in GC cells. In order to discover the roles of miR-1 and sorcin in GC cells, the expression levels of miR-1 and sorcin were examined by RT-qPCR and western blotting in GC cell lines, including SGC7901, SGC7901/ADM and SGC7901/VCR. The half maximal inhibitory concentration $\left(\mathrm{IC}_{50}\right)$ of VCR and ADM was investigated in different gastric cell lines. As presented in Fig. 1A, SGC7901/VCR and SGC7901/ADM exhibited significant resistance to VCR and ADM treatments, respectively. $\mathrm{IC}_{50}$ of ADM to SGC7901/ADM increased 7.65-fold compared with the SGC7901 cells. IC $_{50}$ of VCR to SGC7901/VCR increased 5.94 times compared with the SGC7901 cells. Furthermore, the expression level of miR-1 and mRNA level of sorcin were determined in these three GC cell lines. As presented in Fig. 1B, miR-1 was significantly downregulated in the drug resistant cell lines, which were downregulated to 0.47 and 0.40 in SGC7901/ADM and SGC7901/VCR, respectively, compared with the SGC7901 cells. However, the mRNA expression level of sorcin in these two drug-resistant cell lines was significantly enhanced. The sorcin protein expression level measured by western blot assay also demonstrated the enhanced expression of sorcin in the drug-resistant cell lines (Fig. 1C).

miR -1 reverses the MDR in GC cells. The effect of miR-1 on the MDR in GC cells was investigated. The miR-NC, miR-1 mimics and miR-1 inhibitor were transfected into two drug-resistant GC cells, SGC7901/VCR and SGC7901/ADM. As presented in Fig. 2A, the miR-1 expression was significantly enhanced when miR-1 mimics were transfected in both cell lines. In contrast, the transfection of miR-1 inhibitor downregulated the expression of miR-1 in both cell lines. Furthermore, the $\mathrm{IC}_{50}$ of these two drug-resistant cell lines following transfection was determined. As presented in Fig. 2B, the $\mathrm{IC}_{50}$ of both SGC7901/VCR and SGC7901/ADM treated with miR-1 mimics was significantly decreased and the transfection of miR-1 inhibitor increased the $\mathrm{IC}_{50}$ in both cell lines. The results indicated that miR-1 reversed the multi-drug resistance in GC cell lines.

miR-1 induces GC cell apoptosis. To elucidate how miR-1 reversed the MDR, the effect of miR-1 on the apoptosis of GC cell lines was investigated. As presented in Fig. 3A, SGC7901/ADM and SGC7901/VCR cells were transfected with miR-NC, miR-1 mimics and miR-1 inhibitor and the apoptosis rates were measured by flow cytometry without the treatment 

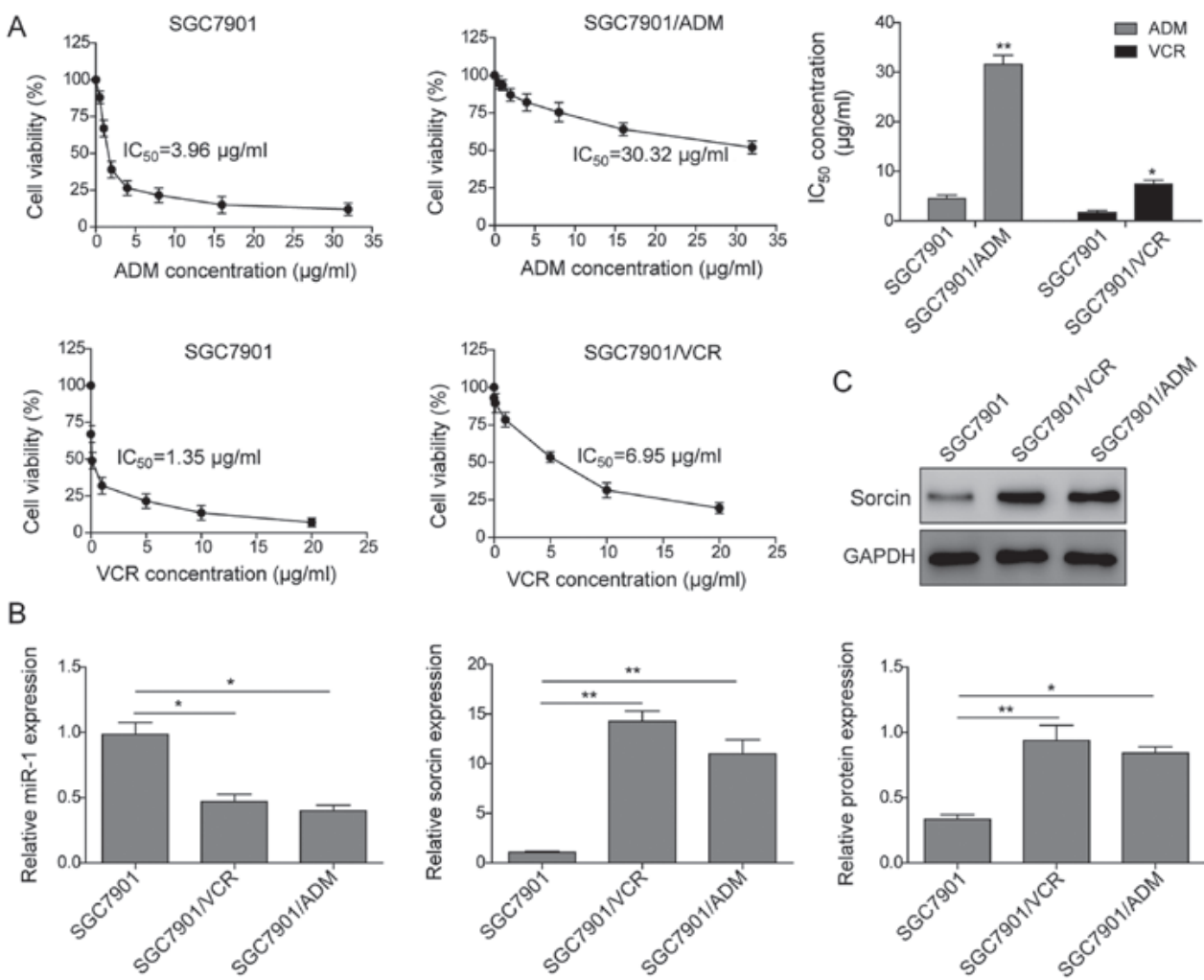

Figure 1. The expression of miR-1 and sorcin in gastric cancer cells. (A) SGC7901, SGC7901/VCR and SGC7901/ADM were treated with different concentrations of ADM or VCR for $48 \mathrm{~h}$, cell viability was detected through MTT assay. $\mathrm{IC}_{50}$ of ACR and ADM were determined according to the cell viability curve. (B) The mRNA expression of miR-1 and sorcin in SGC7901, SGC7901/VCR and SGC7901/ADM cells. (C) The protein expression of sorcin in SGC7901/VCR and SGC7901/ADM cells. Data are presented as the mean \pm standard deviation of three repeated experiments. ${ }^{*} \mathrm{P}<0.05,{ }^{* *} \mathrm{P}<0.01$. miR, microRNA; VCR, vincristine; $\mathrm{ADM}$, adriamycin; $\mathrm{IC}_{50}$, half maximal inhibitory concentration.
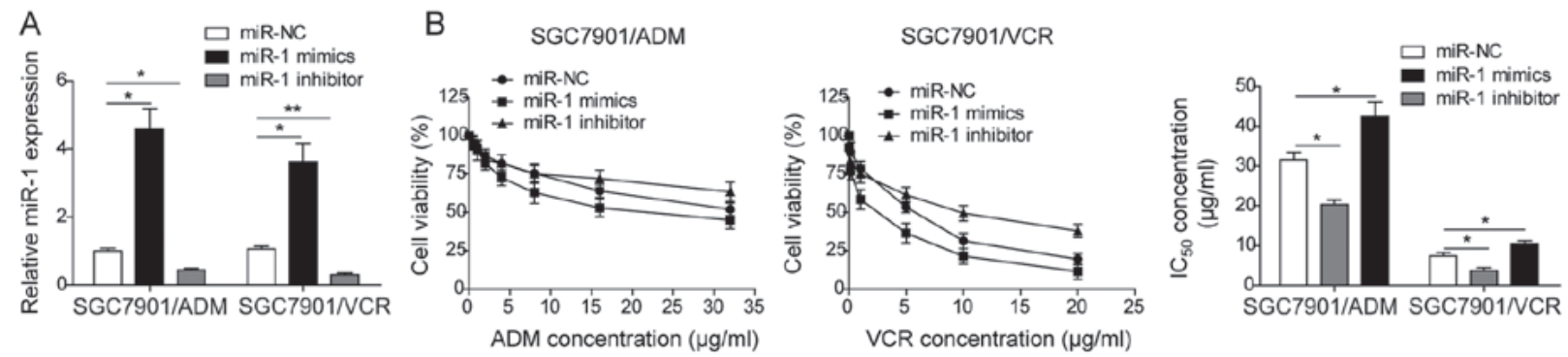

Figure 2. miR-1 reverses the multidrug resistance in gastric cancer cells. (A) miR-1 was upregulated following transfection of miR-1 mimics in SGC7901/VCR and SGC7901/ADM cell lines. miR-1 was downregulated following transfection of miR-1 inhibitor in SGC7901/VCR and SGC7901/ADM cell lines. (B) Half maximal inhibitory concentrations of ADM and VCR were significantly decreased when SGC7901/VCR and SGC7901/ADM cells were treated with miR-1. Data are presented as the mean \pm standard deviation of three repeated experiments. ${ }^{*} \mathrm{P}<0.05,{ }^{* * *} \mathrm{P}<0.01$. miR, microRNA; VCR, vincristine; ADM, adriamycin; miR-NC, scramble control.

of drugs. The results demonstrated that the transfection of miR-1 mimics significantly promoted the apoptosis rates in both SGC7901/ADM and SGC7901/VCR cell lines, but miR-1 inhibitor suppressed cell apoptosis. Furthermore, the transfection of miR-1 mimics significantly enhanced the drug-resistant GC cell apoptosis rates under the treatment of the drugs (Fig. 3B). The apoptosis rate of SGC7901/ADM cells following transfection of miR-1 mimics and treatment with $10 \mu \mathrm{M}$ ADM was $\sim 1.9$ times higher than control groups. Similarly, the apoptosis rate of SGC7901/VCR cells following transfection of miR-1 mimics and treatment with $5 \mu \mathrm{M}$ VCR was 2.1 times higher than the control groups. Meanwhile, the transfection of miR-1 inhibitor significantly decreased the apoptosis rate compared with the control groups when the ADM or VCR drugs were present.

Furthermore, the expression levels of several apoptosis-associated proteins in these transfected drug-resistant GC cell lines were investigated. It was observed that miR-1 upregulated pro-apoptotic proteins including Bax, c-fos and c-jun, but inhibited anti-apoptotic protein BCL-2 and sorcin expression in both SGC7901/ADM and SGC7901/VCR cells. In contrast, miR-1 inhibitor promoted the expression of BCL-2 and sorcin while inhibiting the expression levels of Bax, c-fos and c-jun (Fig. 3C). Similarly, the protein expression levels of these components measured by western blotting assay exhibited the same trends in these drug-resistant GC cell lines (Fig. 3D). 
A
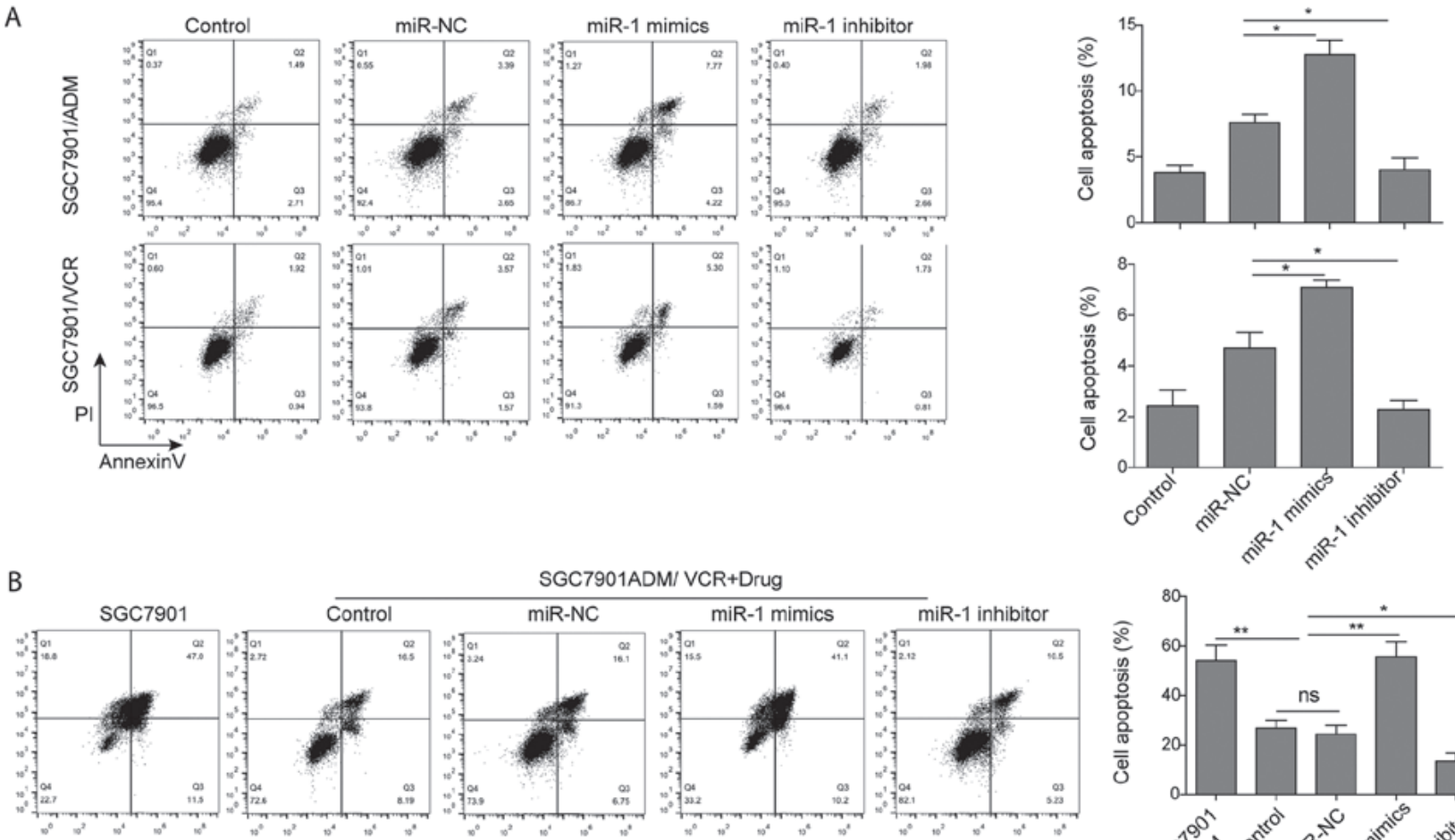

B

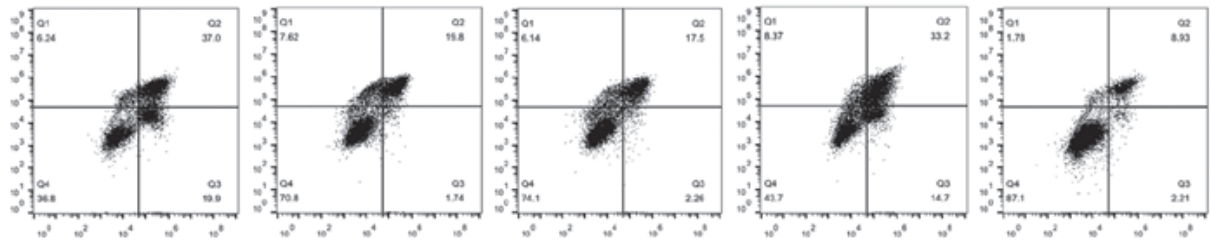

C
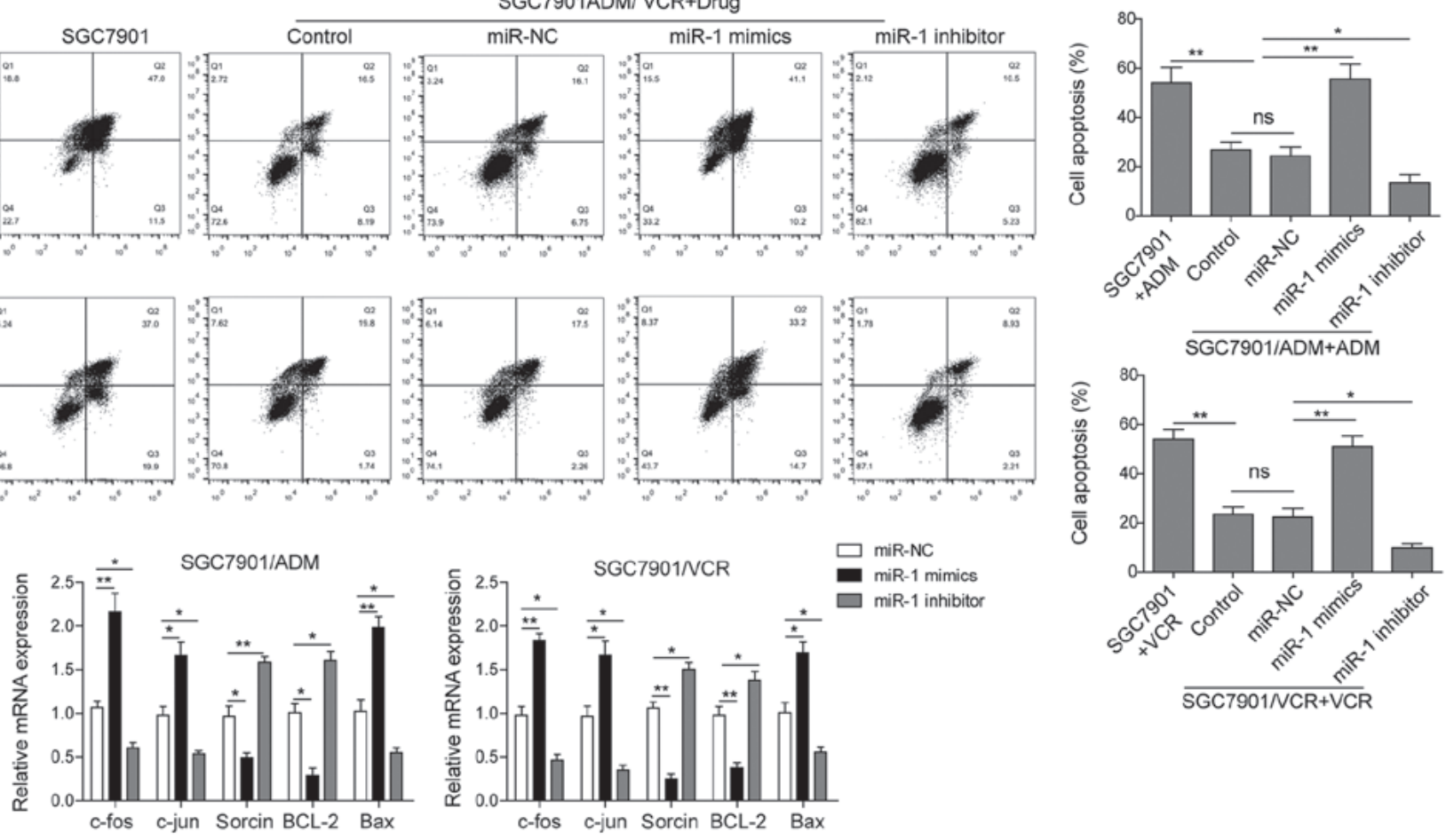

D
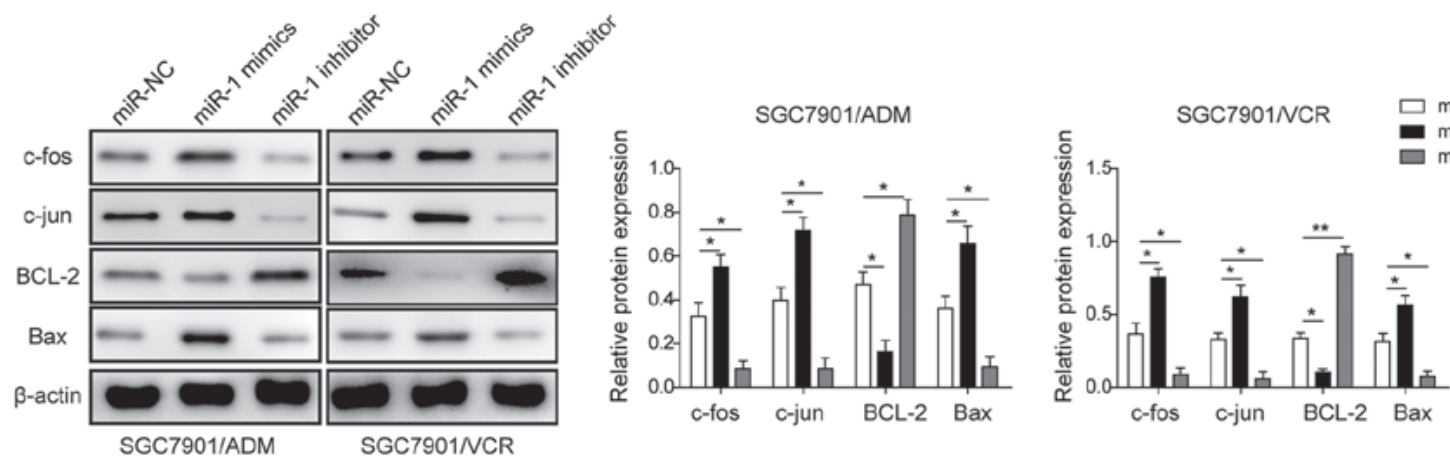

Figure 3. miR-1 induced gastric cancer cell apoptosis. (A) The flow cytometric analysis of apoptosis rates of SGC7901/ADM and SGC7901/VCR with transfection of miR-NC, miR-1 mimics and miR-1 inhibitor. (B) The flow cytometric analysis of apoptosis rates of SGC7901/ADM and SGC7901/VCR cells with transfection of miR-NC, miR-1 mimics and miR-1 inhibitor followed by treatment with ADM and VCR, respectively. The (C) mRNA and (D) protein expression levels of c-fos, c-jun, sorcin, BCL-2 and Bax in SGC7901/ADM and SGC7901/VCR with transfection of miR-NC, miR-1 mimics and miR-1 inhibitor. Data are presented as the mean \pm standard deviation of three repeated experiments. ${ }^{*} \mathrm{P}<0.05,{ }^{* *} \mathrm{P}<0.01$. miR, microRNA; VCR, vincristine; ADM, adriamycin; miR-NC, scramble control; BCL-2, B cell lymphoma-2; Bax, Bcl-2-associated X protein.

miR-1 promotes the drug accumulation in multidrug resistant $G C$ cells. The effect of miR-1 on the drug accumulation in multidrug resistant GC cells was also investigated. Two cell lines, SGC7901/ADM and SGC7901/VCR, were transfected with miR-NC, miR-1 mimics and miR-1 inhibitor. Then, the drug accumulation was measured by flow cytometry with 
A
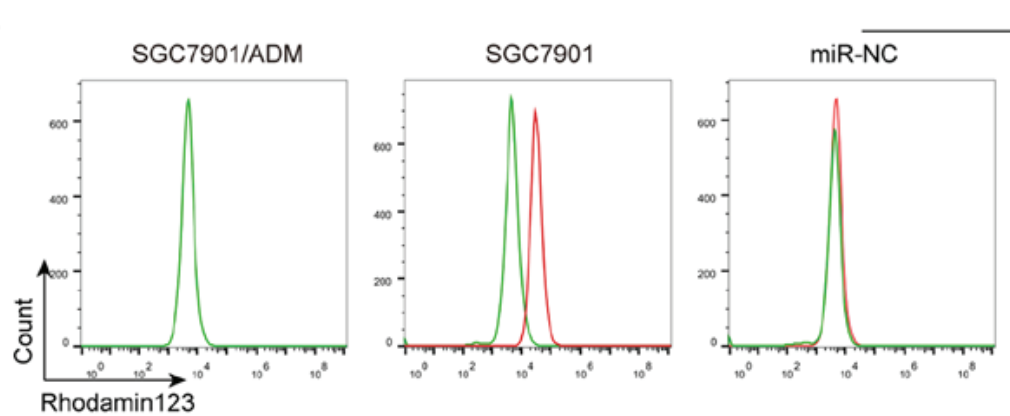

SGC7901/ADM
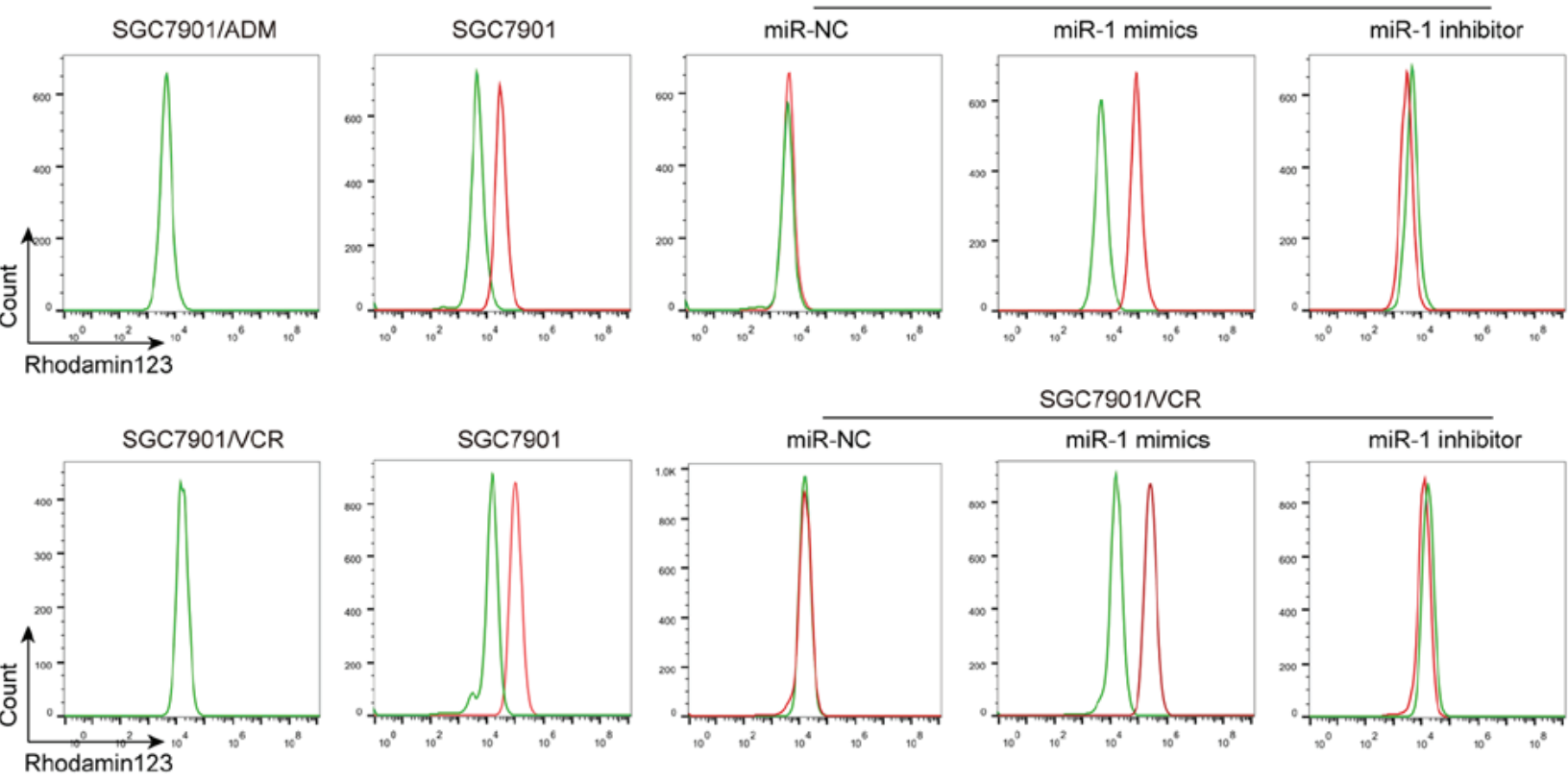

SGC7901NCR
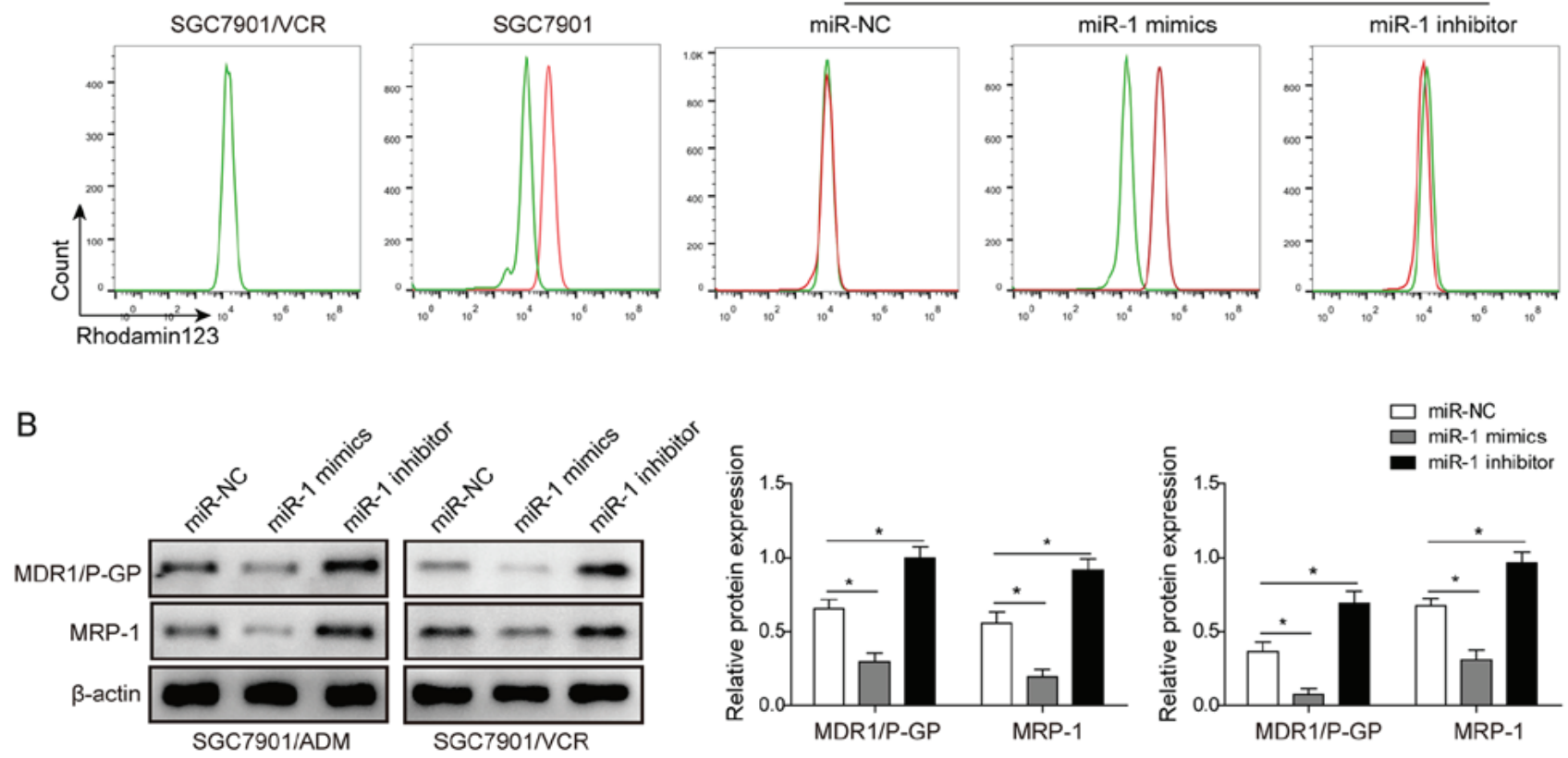

Figure 4. miR-1 promoted the drug accumulation in multidrug resistant gastric cancer cells. (A) Flow cytometric analysis of the Rhodanmin123 accumulation in SGC7901/ADM and SGC7901/VCR cells with transfection of miR-NC, miR-1 mimics and miR-1 inhibitor. (B) The protein expression levels of MDR1/P-gp and MRP-1 in SGC7901/ADM and SGC7901/VCR cells with transfection of miR-NC, miR-1 mimics and miR-1 inhibitor. Data are presented as the mean \pm standard deviation of three repeated experiments. ${ }^{*} \mathrm{P}<0.05$. miR, microRNA; VCR, vincristine; ADM, adriamycin; miR-NC, scramble control; MDR1/P-gp, multidrug resistance protein 1/P-glycoprotein; MRP-1, multidrug resistance-associated protein 1.

Rho123 following the treatment of $10 \mu \mathrm{M}$ ADM and $5 \mu \mathrm{M}$ VCR in SGC7901/ADM and SGC7901/VCR, respectively. The results in Fig. 4A demonstrated that the transfection of miR-1 mimics markedly enhanced the drug accumulation in both SGC7901/ADM and SGC7901/VCR cells. In contrast, the transfection of miR-1 inhibitor inhibited the drug accumulation in these two cell lines. The expression levels of MDR1/P-gp and MRP-1 were determined using western blot analysis following the transfection of miR-1 mimics and miR-1 inhibitor. The results demonstrated that both MDR1/P-gp and MRP-1 were significantly inhibited in SGC7901/ADM and SGC7901/VCR cells transfected with miR-1 mimics. The transfection of miR-1 inhibitor upregulated the MDR1/P-gp and MRP-1 expression levels in SGC7901/ADM and SGC7901/VCR cell lines (Fig. 4B). All these results indicated that the drug accumulation in these two MDR GC cell lines was significantly enhanced by overexpression of miR-1.

Sorcin is a target of $m i R-1$. In order to elucidate the mechanism of miR-1 in the drug-resistant GC cell lines, the interaction between miR-1 and sorcin in these cell lines was investigated. The association between the
miR-1 expression level and the sorcin expression level in the MDR GC cell lines was initially investigated. It was demonstrated that the mRNA expression level and protein level of sorcin in both SGC7901/ADM and SGC7901/VCR cell lines were significantly inhibited when the cells were transfected with miR-1 mimics (Fig. 5A and B). In contrast, the transfection of miR-1 inhibitor in these two cell lines significantly upregulated the sorcin mRNA and protein levels. Furthermore, a dual-luciferase assay was conducted to investigate the interaction between miR-1 and sorcin. The potential target site of miR-1 for sorcin was predicted by the miRDB database (Fig. 5C). Then, the sorcin 3'-UTR fragment was cloned into the dual luciferase reporter vector psiCHECK and the recombinant plasmid was named psiCHECK-wt. The miR-1 targeting sequence in the above sorcin 3'UTR reporter plasmid was also mutated and named psiCHECK-mut. Dual-luciferase reporters containing either psiCHECK-wt or psiCHECK-mut were co-transfected into SGC7901 cells with either miR-NC or miR-1. The group with co-transfection of psiCHECK-wt and miR-1 demonstrated a significant luminescence intensity decrease, suggesting that sorcin may be a target of miR-1 (Fig. 5D). 

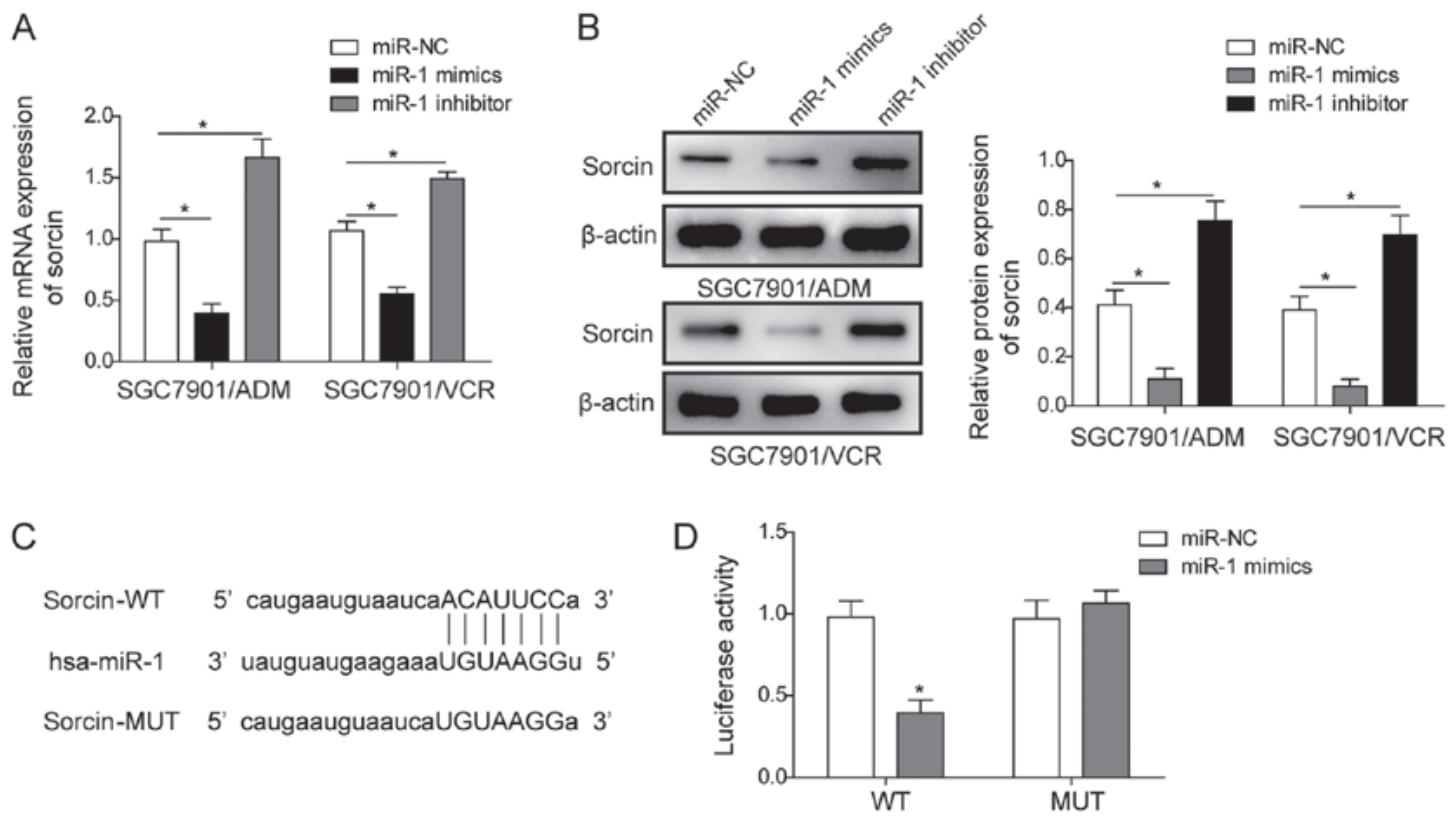

Figure 5. Sorcin was a target of miR-1. (A) mRNA and (B) protein expression levels of sorcin in SGC7901/ADM and SGC7901/VCR cells with transfection of miR-NC, miR-1 mimics and miR-1 inhibitor. (C) The prediction of miR-1 binding sites on sorcin transcript. (D) The luciferase activities in SGC7901 cells co-transfected with miR-1 or miRNA-NC and luciferase reporters containing psiCHECK-wt or psiCHECK-mut. Data are presented as the mean \pm standard deviation of three repeated experiments. ${ }^{*} \mathrm{P}<0.05$. miR, microRNA; VCR, vincristine; ADM, adriamycin; miR-NC, scramble control.

A

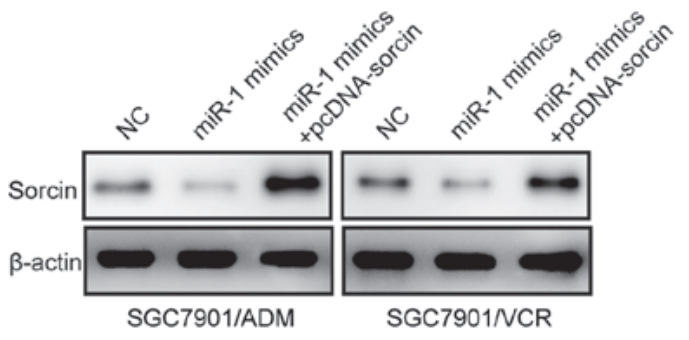

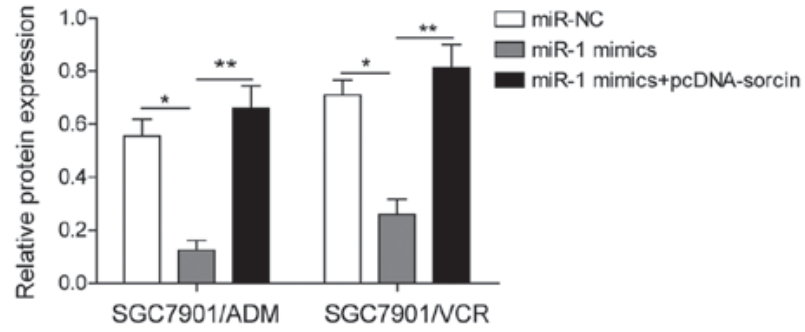

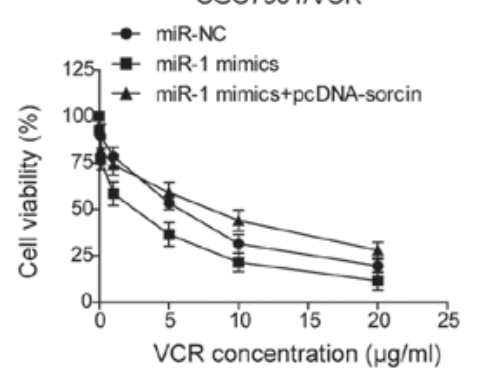

C $\quad \square$ mir-NC

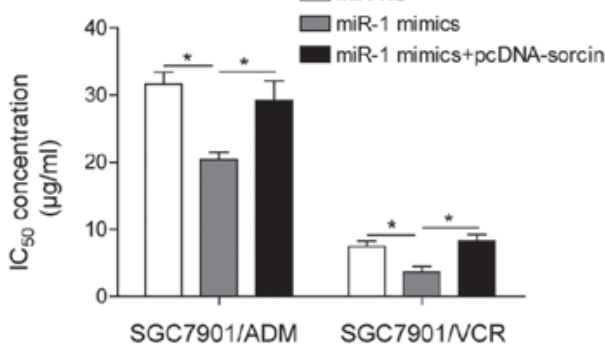

Figure 6. Overexpression of sorcin partially recovered the effect of miR-1 on multidrug resistance in gastric cancer cells. (A) The expression level of sorcin in SGC7901/ADM and SGC7901/VCR cells with transfection of miR-NC, miR-1 mimics and miR-1 mimics with pcDNA-sorcin. (B) IC 50 of ADM to SGC7901/ADM cells following transfection of miR-NC, miR-1 mimics and miR-1 mimics with pcDNA-sorcin. (C) IC 50 $_{50}$ of VCR to SGC7901/VCR cells following transfection of miR-NC, miR-1 mimics and miR-1 mimics with pcDNA-sorcin. Data are presented as the mean \pm standard deviation of three repeated experiments. ${ }^{*} \mathrm{P}<0.05,{ }^{* *} \mathrm{P}<0.01$. miR, microRNA; VCR, vincristine; ADM, adriamycin; $\mathrm{IC}_{50}$, half maximal inhibitory concentration; miR-NC, scramble control.

Overexpression of sorcin in both SGC7901/ADM and SGC7901/VCR cell lines partially reverses the impact of miR-1 on drug resistance. In order to elucidate whether miR-1 regulates the chemosensitivity of MDR GC cell lines through targeting sorcin, sorcin was overexpressed following upregulating miR-1 in SGC7901/ADM and SGC7901/VCR and their impacts on $\mathrm{IC}_{50}$, apoptosis rates and drug accumulation were investigated. SGC7901/ADM and SGC7901/VCR were transfected with miR-NC, miR-1 mimics and miR-1 mimics with pcDNA-sorcin. The sorcin expression levels in different groups were measured by western blot assay (Fig. 6A). The transfection of miR-1 alone significantly downregulated the expression of sorcin in both cell lines. However, co-transfection of miR-1 mimics and pcDNA-sorcin partially recovered the expression of sorcin in both cell lines (Fig. 6A). The MTT assay was used to measure $\mathrm{IC}_{50}$ of $\mathrm{ADM}$ and VCR in different 
A
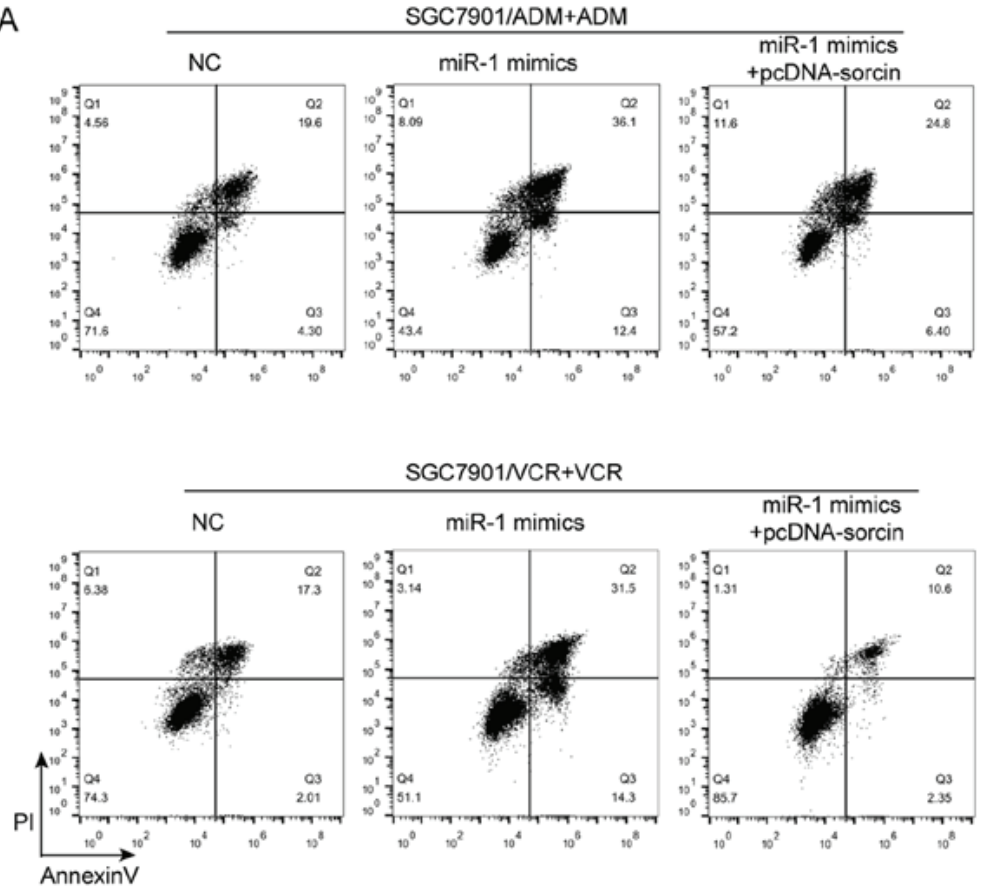
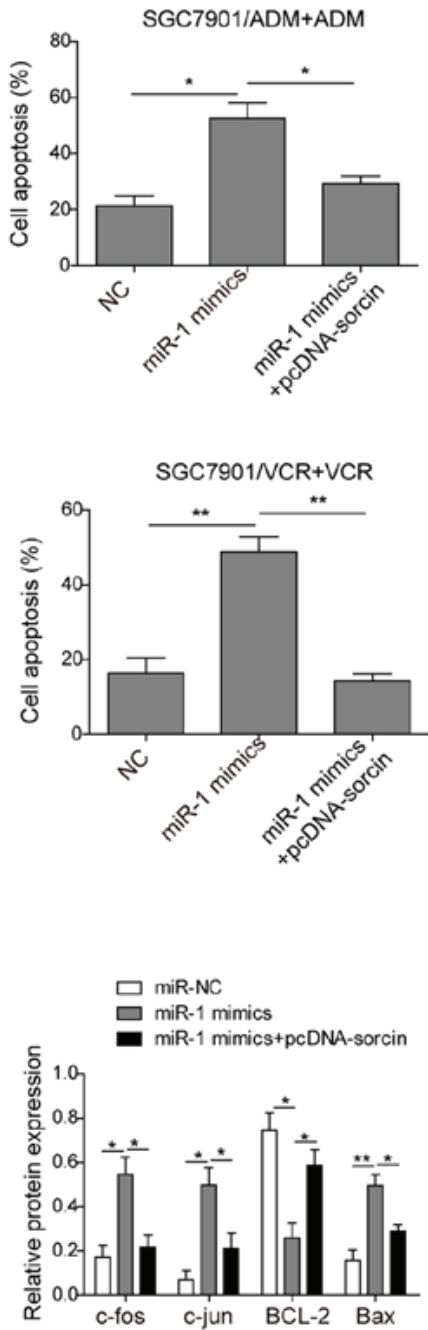

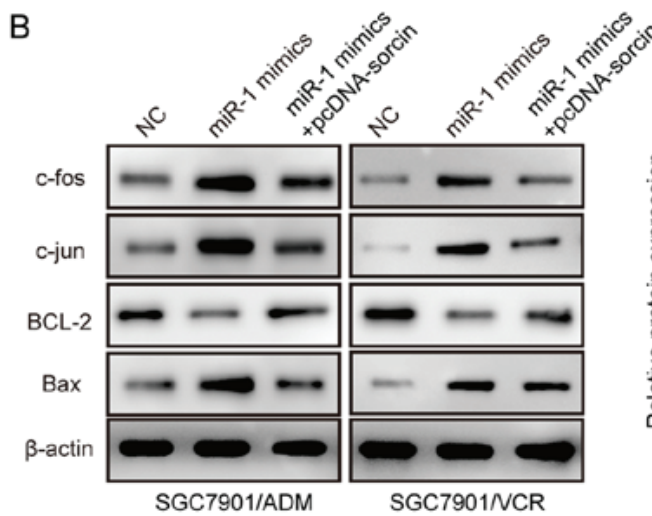

C

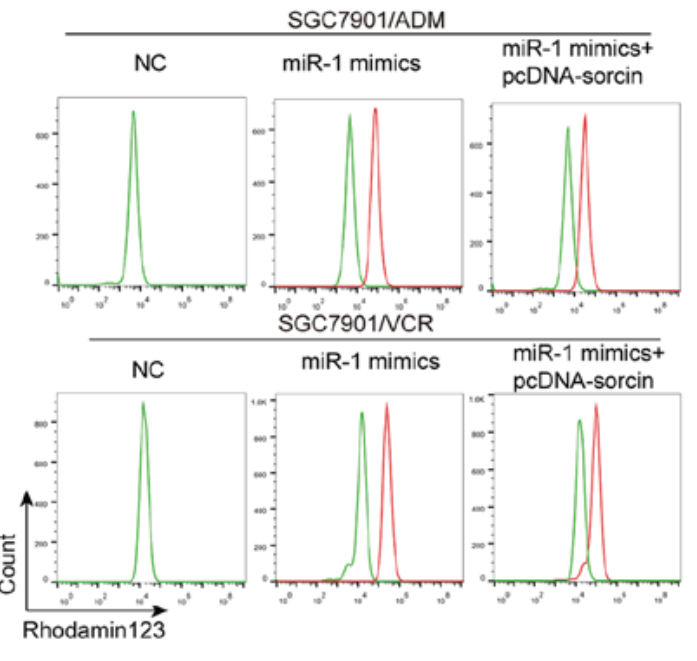

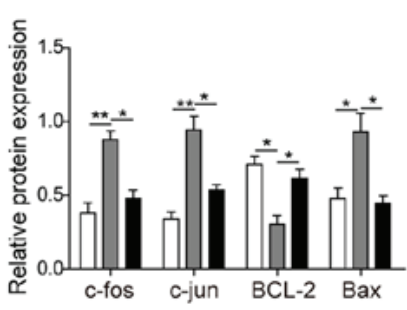
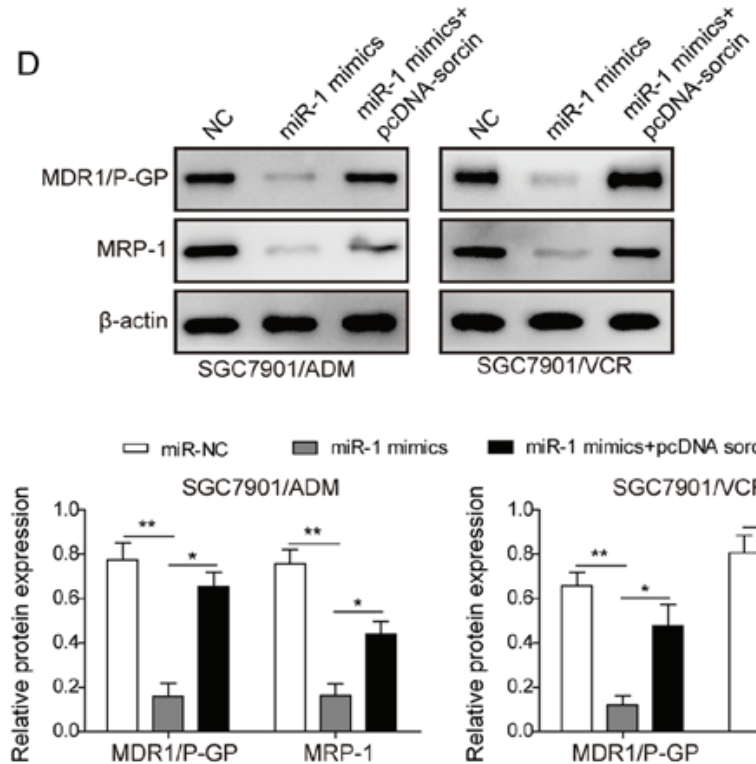

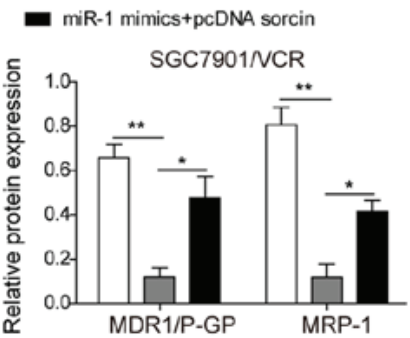

Figure 7. Overexpression of sorcin partially recovered the effect of miR-1 on cell apoptosis and drug accumulation. (A) The cells apoptosis rates of SGC7901/ADM and SGC7901/VCR cells following transfection of miR-NC, miR-1 mimics and miR-1 mimics with pcDNA-sorcin followed by the treatment of ADM and VCR, respectively. The apoptosis rates were measured by flow cytometric analysis. (B) The cell apoptosis associated proteins, including c-fos, c-jun, BCL-2 and Bax were analyzed in SGC7901/ADM and SGC7901/VCR cells following transfection of miR-NC, miR-1 mimics and miR-1 mimics with pcDNA-sorcin. (C) The drug accumulation of Rhodamine 123 in SGC7901/ADM and SGC7901/VCR cells following transfection of miR-NC, miR-1 mimics and miR-1 mimics with pcDNA-sorcin were analyzed by flow cytometry. (D) The expression levels of MDR1/P-gp and MRP-1 were analyzed in SGC7901/ADM and SGC7901/VCR cells following transfection of miR-NC, miR-1 mimics and miR-1mimics with pcDNA-sorcin. Data are presented as the mean \pm standard deviation of three repeated experiments. "P<0.05, " $\mathrm{P}<0.01$. miR, microRNA; VCR, vincristine; ADM, adriamycin; miR-NC, scramble control; BCL-2, B cell lymphoma-2; Bax, Bcl-2-associated X protein; MDR1/P-gp, multidrug resistance protein 1/P-glycoprotein; MRP-1, multidrug resistance-associated protein 1. 
groups. The results demonstrated that the transfection of miR-1 mimics in both cell lines decreased the $\mathrm{IC}_{50}$. However, the co-transfection of miR-1 mimics and pcDNA-sorcin partially restored the $\mathrm{IC}_{50}$ from 20.4 to 29.2 , and 3.7 to 8.3 in SGC7901/ADM and SGC7901/VCR cells, respectively. These results demonstrated that the effect of miR-1 on drug resistance was partially reversed by overexpressing sorcin in MDR GC cells (Fig. 6B and C).

Secondly, SGC7901/ADM and SGC7901/VCR were co-transfected with miR-1 mimics and pcDNA-sorcin and then treated with $10 \mu \mathrm{M}$ ADM and $5 \mu \mathrm{M}$ VCR, respectively. The flow cytometry results indicated that co-transfection of pcDNA-sorcin with miR-1 mimics partially reduced the apoptosis rates compared with the groups that were only transfected with miR-1 mimics (Fig. 7A). From the western blot assay, it was demonstrated that by overexpressing sorcin in SGC7901/ADM and SGC7901/VCR cells, the upregulation of the apoptosis-associated proteins, including Bax, c-fos and c-jun, and downregulation of BCL-2 induced by transfection of miR-1 mimics, were both partially reversed (Fig. 7B). Finally, the drug accumulation in SGC7901/ADM and SGC7901/VCR cells was tested following co-transfection of miR-1 mimics and pcDNA-sorcin. As presented in Fig. 7C, the flow cytometric analysis indicated the accumulation of Rho123 in SGC7901/ADM and SGC7901/VCR cells following the overexpression of sorcin was markedly decreased compared with the groups which were only transfected with miR-1 mimics. The western blot analysis demonstrated that the expression of MDR1/P-gp and MRP-1 in SGC7901/ADM and SGC7901/VCR cells were partially recovered when the cells were overexpressed with sorcin (Fig. 7D). Based on the results, the impact of miR-1 on MDR GC cells could be partially reversed by the overexpression of sorcin, which indicated that miR-1 regulated the MDR in GC cells by inhibiting the expression of sorcin.

\section{Discussion}

GC is a highly life-threating disease due to the lack of efficient early diagnostic methods and treatment of tumor metastases (1). Most patients with GC are diagnosed at an advanced stage and lose the opportunity to be treated by surgery. Alternatively, chemotherapy is the preferable therapeutic option for those patients. However, developed MDR in chemotherapy becomes a major obstacle leading to the failure of treatment $(3,4)$. Therefore, it is of interest to elucidate the mechanism of MDR. There have been several mechanisms reported, such as increased drug efflux, dysfunction of pro-apoptotic proteins, mutation of target genes and inactivation of detoxification enzymes (28). However, the mechanism of chemoresistance remains to be elucidated. In the present study, it was demonstrated that miR-1 was highly downregulated in SGC7901/ADM and SGC7901/VCR cell lines. Overexpression of miR-1 in these MDR GC cells decreased $\mathrm{IC}_{50}$ but increased cell apoptosis rates and promoted drug accumulation in cancer cells. It was also demonstrated that sorcin was the target of miR-1 in GC. Furthermore, overexpression of sorcin could partially reverse the effects of miR-1 on the MDR of GC cells. The role of miR-1 in MDR GC cells makes it a potential therapeutic target for a successful clinical outcome.
It has been reported that miRNA participated in the development of drug resistance and metastasis in GC cells (29). miRNA microarray and bioinformatics were widely used to examine the miRNAs levels and their correlation with progression and prognosis of GC (30). For instance, Cao et al (31) reported that miRNA-647 regulated drug resistance and metastasis of GC cells via inhibiting ANK2. Yan et al (32) demonstrated that the recurrence rate of GC could be discriminated by the seven upregulated and five downregulated miRNAs. Therefore, it is of importance to elucidate the mechanism of miRNAs on the regulation of MDR in GC for improving the treatment efficiency and discovering novel therapeutic targets. Among miRNAs, miR-1 was demonstrated to be widely downregulated in various types of cancer, including lung (33), prostate (34) and colon (35) cancer and GC. In GC, Tsai et al (36) demonstrated that downregulation of miR-1 directly regulated endothelin-1 expression to enhance the cell proliferation and metastasis, and finally inhibited cell apoptosis. It was also reported that aberrant expression of miR-1 impacted the chemoresistance in cancers. For instance, overexpression of miR-1 in lung cancer cells enhanced cells response rate to an anticancer drug (doxorubicin) (37). However, the status of miR-1 and its underlining mechanism to regulate the MDR in GC cells are still unclear. Therefore, the expression levels of miR-1 were investigated in the MDR cell lines in the present study. It was demonstrated that miR-1 was downregulated in the MDR gastric cell lines, indicating that miR-1 might serve an important role in the drug resistance of GC. Furthermore, when the MDR GC cells were transfected to overexpress miR-1, the chemosensitivity of these MDR GC cells significantly increased, indicating the regulation function of miR-1 in the drug resistance in $\mathrm{GC}$ cells.

In order to uncover the mechanism of miR-1 for reversing drug resistance properties of MDR GC cells, it was demonstrated that the overexpression of miR-1 could upregulate the pro-apoptotic proteins including Bax, c-fos and c-jun, but inhibit the anti-apoptotic protein $\mathrm{Bcl}-2$, which promoted the cell apoptosis with the treatment of chemotherapeutic drugs. These findings are consistent with a previous report, which demonstrated that ectopic miR-1 expression could decrease cell viability in lung cancer cells in response to the chemotherapeutic drug (37). Apoptosis has been proved to be a major mechanism of programmed cell death and most of the chemotherapeutic drugs induce apoptosis of cancer cells. For instance, Ma et al (4) demonstrated that the inhibition of cell apoptosis induced chemoresistance in GC, which was regulated by overexpression of hepatocyte nuclear factor- $4 \alpha$. It is well known that in the process of chemotherapy-induced apoptosis, Bcl-2 is a critical survival factor which inhibits apoptosis in various cell systems (38). In many cases, the resistance of cancer cells to chemotherapeutic drugs may be caused by the overexpression of Bcl-2 (39,40). Also, Bcl-2/Bax was recognized to be critically involved in regulating mitochondrial function, which ultimately modulates cell apoptosis (39). A number of studies demonstrated the high expression ratio of $\mathrm{Bcl}-2 / \mathrm{Bax}$ in chemoresistant cancer cells $(40,41)$. Furthermore, the AP-1 proteins, composed of c-fos/c-jun, were reported to work as tumor suppressors by inducing apoptosis of cells (41). 
On the other hand, drug efflux is also recognized as an important pathway to generate drug resistance in chemotherapy of many cancer types (42). P-gp and MRP-1 are members of the ATP-binding cassette transporters, which serve as drug efflux pumps that extrude chemotherapeutic agents from MDR cancer cells, inducing drug resistance $(43,44)$. P-gp and MRP-1 are usually overexpressed in many types of MDR cancer to increase drug efflux, which correlates with poor prognosis and relapse in human cancers $(42,45)$. For instance, it was demonstrated that in human hepatocellular carcinoma cells, MDR could be significantly reversed by inhibiting P-gp and MRP1 expression using indomethacin and SC236 (45). Recently, Wang et al (45) demonstrated that the multidrug resistant leukemic cell proliferation was inhibited by reducing P-gp expression via the knockdown of Wnt receptor Frizzled-1. By overexpressing miR-1 mimics in MDR GC cells, the present study demonstrated that the drug accumulation in those MDR GC cells were significantly enhanced and the expression levels of MDR1/P-gp and MRP-1 were lower than those of the control groups.

All these data indicated that miR-1 overexpression could reverse drug resistance through promoting cell apoptosis and inhibiting drug efflux pumps. However, the mechanism of miR-1 to promote the cell apoptosis and drug accumulation in MDR GC cells remains unclear. The present results indicated that the MDR in GC cells could be regulated by miR-1 via targeting sorcin. Sorcin is a cytoplasmic protein with a molecular mass of $22 \mathrm{kDa}$ and is part of the penta-EF-hand protein family. In a number of drug-resistant tumor cell lines, sorcin was reported to be overexpressed, which was consistent with the results that sorcin was highly overexpressed in the SGC7901/ADM and SGC7901/VCR cells. In addition, more evidences indicated that sorcin was involved in MDR in a wide number of tumor types, including colorectal cancer cells, GC cells, leukemia and lung cancer cells $(5,13,15,46)$. It was reported that sorcin expression upregulated $\mathrm{P}$-gp expression via a cyclic adenosine monophosphate response element, which induced the drug efflux in leukemia cells (9). In human breast cancer, Gong et al (12) demonstrated that sorcin was overexpressed in the human serum of the neoadjuvant chemotherapy (NAC)-resistant patients as compared with that of NAC-sensitive patients. Therefore, the present study systematically investigated the interaction between miR-1 and sorcin in MDR GC cells and demonstrated that overexpression of miR-1 could promote the chemotherapeutic sensitivity, but overexpression of sorcin in those miR-1 mimics transfected groups could partially reverse the impact of miR-1 in MDR GC cells. The reason that the impact of miR-1 in MDR GC cells was only partially but not totally reversed by overexpression of sorcin may be that sorcin is not the only protein that is regulated by miR-1. For instance, miR-1 was reported to regulate the stromal cell-derived factor 1 and angiogenesis-associated growth factors to regulate cell chemoresistance in different types of cancer $(19,20)$. These results indicated that in MDR GC cells, miR-1 regulated the expression level of sorcin, which controls the cell apoptosis and drug accumulation.

In conclusion, the present findings demonstrated that miR-1 was downregulated and sorcin was upregulated in multidrug resistant GC cells. Furthermore, it was demonstrated that miR-1 reversed the MDR in GC cells via inhibiting the expression of sorcin, which promoted the accumulation of intracellular drugs and enhanced the apoptosis of cells. Hence, by understanding the involved mechanisms of miR-1 and sorcin in multidrug resistant GC cells, miR-1 may be considered a valuable target for chemotherapy of MDR GC. However, the present study only demonstrated the function of miR-1 in MDR GC cells. A future in vivo investigation should be conducted to further promote the usage of miR-1 as a therapeutic target in MDR $\mathrm{GC}$ treatment, which is our future direction.

\section{Acknowledgements}

Not applicable.

\section{Funding}

This study was supported by Hunan Provincial Natural Science Foundation (grant no. 2016JJ3163).

\section{Availability of data and materials}

The datasets used and/or analyzed during the current study are available from the corresponding author on reasonable request.

\section{Authors' contributions}

LMD and TT conceived and designed the experiments. HG performed the experiments. LMD, TYZ and XFX analyzed the data and wrote the manuscript. All authors read and approved the final manuscript.

\section{Ethics approval and consent to participate}

Not applicable.

\section{Patient consent for publication}

Not applicable.

\section{Competing interests}

The authors declare that they have no competing interests.

\section{References}

1. Zhang D and Fan D: New insights into the mechanisms of gastric cancer multidrug resistance and future perspectives. Future Oncol 6: 527-537, 2010.

2. Du X, Liu B, Luan X, Cui Q and Li L: miR-30 decreases multidrug resistance in human gastric cancer cells by modulating cell autophagy. Exp Ther Med 15: 599-605, 2018.

3. Ozben T: Mechanisms and strategies to overcome multiple drug resistance in cancer. FEBS Lett 580: 2903-2909, 2006.

4. Ma Y, Wei X and Wu Z: HNF-4 $\alpha$ promotes multidrug resistance of gastric cancer cells through the modulation of cell apoptosis. Oncol Lett 14: 6477-6484, 2017.

5. Colotti G, Poser E, Fiorillo A, Genovese I, Chiarini V and Ilari A: Sorcin, a calcium binding protein involved in the multidrug resistance mechanisms in cancer cells. Molecules 19: 13976-13989, 2014.

6. Ilari A, Johnson KA, Nastopoulos V, Verzili D, Zamparelli C, Colotti G, Tsernoglou D and Chiancone E: The crystal structure of the sorcin calcium binding domain provides a model of $\mathrm{Ca}^{2+}$-dependent processes in the full-length protein. $\mathrm{J} \mathrm{Mol}$ Biol 317: 447-458, 2002. 
7. Genovese I, Fiorillo A, Ilari A, Masciarelli S, Fazi F and Colotti G: Binding of doxorubicin to Sorcin impairs cell death and increases drug resistance in cancer cells. Cell Death Dis 8: e2950, 2017.

8. Deng L, Su T, Leng A, Zhang X, Xu M, Yan L, Gu H and Zhang G: Upregulation of soluble resistance-related calcium-binding protein (sorcin) in gastric cancer. Med Oncol 27: 1102-1108, 2010.

9. Yamagishi N, Nakao R, Kondo R, Nishitsuji M, Saito Y, Kuga T, Hatayama $\mathrm{T}$ and Nakayama Y: Increased expression of sorcin is associated with multidrug resistance in leukemia cells via up-regulation of MDR1 expression through cAMP response element-binding protein. Biochem Biophys Res Commun 448: 430-436, 2014

10. Van der Bliek AM, Meyers MB, Biedler JL, Hes E and Borst P: A 22-kd protein (sorcin/V19) encoded by an amplified gene in multidrug-resistant cells, is homologous to the calcium-binding light chain of calpain. EMBO J 5: 3201-3208, 1986.

11. He Q, Zhang G, Hou D, Leng A, Xu M, Peng J and Liu T: Overexpression of sorcin results in multidrug resistance in gastric cancer cells with up-regulation of P-gp. Oncol Rep 25: 237-243, 2011

12. Gong Z, Sun P, Chu H, Zhu H, Sun D and Chen J: Overexpression of sorcin in multidrug-resistant human breast cancer. Oncol Lett 8: 2393-2398, 2014.

13. Yi H, Yang YX, Tang CE, Chen ZC, Zhang GY and Xiao ZQ: Sorcin overexpression and multidrug resistance in human gastric cancer cells. Zhong Nan Da Xue Xue Bao Yi Xue Ban 31: 340-344, 349, 2006 (In Chinese).

14. Xu P, Jiang YF and Wang JH: shRNA-mediated silencing of sorcin increases drug chemosensitivity in myeloma KM3/DDP and U266/ADM cell lines. Int J Clin Exp Pathol 8: 2300-2310, 2015.

15. Hu Y, Li S, Yang M, Yan C, Fan D, Zhou Y, Zhang Y, Yagüe E and Xiong D: Sorcin silencing inhibits epithelial-to-mesenchymal transition and suppresses breast cancer metastasis in vivo. Breast Cancer Res Treat 143: 287-299, 2014.

16. Macfarlane LA and Murphy PR: MicroRNA: Biogenesis, function and role in cancer. Curr Genomics 11: 537-561, 2010.

17. Garzon R, Marcucci G and Croce CM: Targeting microRNAs in cancer: Rationale, strategies and challenges. Nat Rev Drug Discov 9: 775-789, 2010.

18. Han C, Yu Z, Duan Z and Kan Q: Role of microRNA-1 in human cancer and its therapeutic potentials. BioMed Res Int 2014: 428371,2014

19. Xie M, Dart DA, Guo T, Xing XF, Cheng XJ, Du H, Jiang WG Wen XZ and Ji JF: MicroRNA-1 acts as a tumor suppressor microRNA by inhibiting angiogenesis-related growth factors in human gastric cancer. Gastric Cancer 21: 41-54, 2018.

20. Li J, Guan J, Long X, Wang Y and Xiang X: mir-1-mediated paracrine effect of cancer-associated fibroblasts on lung cancer cell proliferation and chemoresistance. Oncol Rep 35: 3523-3531, 2016.

21. Liu M, Zheng S, Zhang X, Guo H, Shi X, Kang X, Qu Y, Hu Z and Tian J: Cerenkov luminescence imaging on evaluation of early response to chemotherapy of drug-resistant gastric cancer. Nanomedicine 14: 205-213, 2018.

22. Wang Y, Wu K, Yang Z, Zhao Q, Fan D, Xu P, Nie Y and Fan D: Multidrug-resistance related long non-coding RNA expression profile analysis of gastric cancer. PLoS One 10: e0135461, 2015.

23. Xu YC, Liu X, Li M, Li Y, Li CY, Lu Y, Sanches J, Wang L, Du Y Mao LM, et al: A novel mechanism of doxorubicin resistance and tumorigenesis mediated by microRNA-501-5p-suppressed BLID. Mol Ther Nucleic Acids 12: 578-590, 2018

24. Koontz MZ, Horning SJ, Balise R, Greenberg PL, Rosenberg SA, Hoppe RT and Advani RH: Risk of therapy-related secondary leukemia in Hodgkin lymphoma: The Stanford University experience over three generations of clinical trials. J Clin Oncol 31: $592-598,2013$

25. Waqar SN and Morgensztern D: Treatment advances in small cell lung cancer (SCLC). Pharmacol Ther 180: 16-23, 2017.

26. Dower CM, Bhat N, Gebru MT, Chen L, Wills CA, Miller BA and Wang HG: Targeted inhibition of ULK1 promotes apoptosis and suppresses tumor growth and metastasis in neuroblastoma. Mol Cancer Ther 17: 2365-2376, 2018.

27. Livak KJ and Schmittgen TD: Analysis of relative gene expression data using real-time quantitative PCR and the 2(-Delta Delta C(T)) Method. Methods 25: 402-408, 2001.

28. Chen QN, Wei CC, Wang ZX and Sun M: Long non-coding RNAs in anti-cancer drug resistance. Oncotarget 8: 1925-1936, 2017.

29. Sui H, Cai GX, Pan SF, Deng WL, Wang YW, Chen ZS, Cai SJ, Zhu HR and Li Q: miR200c attenuates P-gp-mediated MDR and metastasis by targeting JNK2/c-Jun signaling pathway in colorectal cancer. Mol Cancer Ther 13: 3137-3151, 2014.
30. Xie M, Dart DA, Owen S, Wen X, Ji J and Jiang W: Insights into roles of the miR-1, -133 and -206 family in gastric cancer (Review). Oncol Rep 36: 1191-1198, 2016.

31. Cao W, Wei W, Zhan Z, Xie D, Xie Y and Xiao Q: Regulation of drug resistance and metastasis of gastric cancer cells via the microRNA647-ANK2 axis. Int J Mol Med 41: 1958-1966, 2018.

32. Yan Z, Xiong Y, Xu W, Gao J, Cheng Y, Wang Z, Chen F and Zheng G: Identification of hsa-miR-335 as a prognostic signature in gastric cancer. PLoS One 7: e40037, 2012.

33. MatakiH,EnokidaH,Chiyomaru T,MizunoK,MatsushitaR,Goto Y, Nishikawa R, Higashimoto I, Samukawa T, Nakagawa M, et al: Downregulation of the microRNA-1/133a cluster enhances cancer cell migration and invasion in lung-squamous cell carcinoma via regulation of Coronin1C. J Hum Genet 60: 53-61, 2015.

34. Chang YS, Chen WY, Yin JJ, Sheppard-Tillman H, Huang J and Liu YN: EGF receptor promotes prostate cancer bone metastasis by downregulating miR-1 and activating TWIST1. Cancer Res 75: 3077-3086, 2015.

35. Xu L, Zhang Y, Wang H, Zhang G, Ding Y and Zhao L: Tumor suppressor miR-1 restrains epithelial-mesenchymal transition and metastasis of colorectal carcinoma via the MAPK and PI3K/AKT pathway. J Transl Med 12: 244, 2014

36. Tsai KW, Hu LY, Chen TW, Li SC, Ho MR, Yu SY, Tu YT, Chen WS and Lam HC: Emerging role of microRNAs in modulating endothelin-1 expression in gastric cancer. Oncol Rep 33: 485-493, 2015.

37. Nasser MW, Datta J, Nuovo G, Kutay H, Motiwala T, Majumder S, Wang B, Suster S, Jacob ST and Ghoshal K: Down-regulation of micro-RNA-1 (miR-1) in lung cancer. Suppression of tumorigenic property of lung cancer cells and their sensitization to doxorubicin-induced apoptosis by miR-1. J Biol Chem 283: 33394-33405, 2008.

38. Beale PJ, Rogers P, Boxall F, Sharp SY and Kelland LR: BCL-2 family protein expression and platinum drug resistance in ovarian carcinoma. Br J Cancer 82: 436-440, 2000.

39. Chen J, Wang L, Tang Y, Gong G, Liu L, Chen M, Chen Z, Cui Y, Li C, Cheng X, et al: Maspin enhances cisplatin chemosensitivity in bladder cancer T24 and 5637 cells and correlates with prognosis of muscle-invasive bladder cancer patients receiving cisplatin based neoadjuvant chemotherapy. J Exp Clin Cancer Res 35: 2, 2016.

40. Hu Y, Cheng X, Li S, Zhou Y, Wang J, Cheng T, Yang M and Xiong D: Inhibition of sorcin reverses multidrug resistance of K562/A02 cells and MCF-7/A02 cells via regulating apoptosis-related proteins. Cancer Chemother Pharmacol 72: 789-798, 2013.

41. Gottesman MM, Fojo T and Bates SE: Multidrug resistance in cancer: role of ATP-dependent transporters. Nat Rev Cancer 2: 48-58, 2002.

42. Tainton KM, Smyth MJ, Jackson JT, Tanner JE, Cerruti L, Jane SM, Darcy PK and Johnstone RW: Mutational analysis of P-glycoprotein: Suppression of caspase activation in the absence of ATP-dependent drug efflux. Cell Death Differ 11: 1028-1037, 2004.

43. de Groot DJ, van der Deen M, Le TK, Regeling A, de Jong S and de Vries EG: Indomethacin induces apoptosis via a MRP1-dependent mechanism in doxorubicin-resistant small-cell lung cancer cells overexpressing MRP1. Br J Cancer 97: 1077-1083, 2007.

44. Ye CG, Wu WK, Yeung JH, Li HT, Li ZJ, Wong CC, Ren SX, Zhang L, Fung KP and Cho CH: Indomethacin and SC236 enhance the cytotoxicity of doxorubicin in human hepatocellular carcinoma cells via inhibiting P-glycoprotein and MRP1 expression. Cancer Lett 304: 90-96, 2011.

45. Wang $\mathrm{YH}$, Imai $\mathrm{Y}$, Shiseki $\mathrm{M}$, Tanaka $\mathrm{J}$ and Motoji $\mathrm{T}$ : Knockdown of the Wnt receptor Frizzled-1 (FZD1) reduces MDR1/P-glycoprotein expression in multidrug resistant leukemic cells and inhibits leukemic cell proliferation. Leuk Res 67: 99-108, 2018.

46. Tuo H, Shu F, She S, Yang M, Zou XQ, Huang J, Hu HD, Hu P, Ren H,Peng SF, et al: Sorcin induces gastric cancer cell migration and invasion contributing to STAT3 activation. Oncotarget 8: 104258-104271, 2017.

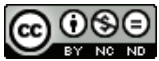

This work is licensed under a Creative Commons Attribution-NonCommercial-NoDerivatives 4.0 International (CC BY-NC-ND 4.0) License. 